\title{
Impaired in Vitro Macrophage Function in HIV-1 Infected Remunerated Blood Donors with History of Oral Iron Intake
}

\author{
Debasish Chattopadhya ${ }^{1,2^{*}}$, Alice Verghese ${ }^{1}$ \\ ${ }^{1}$ Centre for AIDS and Related Diseases, National Centre for Disease Control, Delhi, India \\ ${ }^{2}$ Department of Microbiology, Faculty of Medicine and Health Sciences, SGT University, Gurgaon, India \\ Email: ^dchattopadhya27@gmail.com
}

How to cite this paper: Chattopadhya, D. and Verghese, A. (2018) Impaired in Vitro Macrophage Function in HIV-1 Infected Remunerated Blood Donors with History of Oral Iron Intake. Journal of Biosciences and Medicines, 6, 1-24.

https://doi.org/10.4236/jbm.2018.64001

Received: March 2, 2018

Accepted: April 5, 2018

Published: April 8, 2018

Copyright $\odot 2018$ by authors and Scientific Research Publishing Inc. This work is licensed under the Creative Commons Attribution International License (CC BY 4.0).

http://creativecommons.org/licenses/by/4.0/

\section{Open Access}

\begin{abstract}
Both HIV-1 infection and iron overload are independently associated with infection by Mycobacterium tuberculosis due to impaired macrophage function. A prospective study of in vitro assessment of macrophage function was undertaken in a group of asymptomatic HIV-1 infected remunerated (professional) blood donors with $(n=54)$ or without $(n=54)$ prevalent practice of oral iron intake (subgroups I and II respectively). The assessment was carried out at enrolment as well as at the point of development of AIDS related illness (ARI). The subgroup I showed higher levels of pro-inflammatory cytokines viz. IL- $1 \beta$, IL- 6 and IL-8 in serum, but lowered levels of IL-12p70 in serum as well as in supernatant of monocyte derived macrophage (MDM) cultures both at enrolment and at the point of development of ARI in the subset of cases that developed pulmonary tuberculosis (PT) on follow up compared to the subset that developed categories of ARI other than pulmonary tuberculosis (non-PT) on follow up. The subgroup II of HIV-1 positive donors did not show any such alterations at enrolment or at the point of development of PT or non-PT categories of ARI on follow up. There was significant depression of nitrite level in serum as well as that produced by MDM culture at enrolment in subgroup I regardless of category of ARI developed on follow up while in subgroup II there was significant elevation in these levels at enrolment, more among cases developing PT than those developing non-PT category of ARI. The subgroup I demonstrated increased production of superoxide at enrolment. The present study suggested that depressed production of nitrite and IL-12p70 by macrophages induced by iron overload may be responsible for greater susceptibility of HIV-1 positive donors to M. tuberculosis while superoxide may be a less powerful anti-mycobacterial tool.
\end{abstract}




\section{Keywords}

HIV-1, Pro-Inflammatory Cytokines, Nitrite, Superoxide, IL-12p70, MDMb

Culture, Pulmonary Tuberculosis

\section{Introduction}

Gamma interferon (IFN- $\gamma$ ), a potent pro-inflammatory cytokine secreted by monocytes/macrophages, is considered to play a key role in defense against $M y$ cobacterium tuberculosis infection mediated generation of free radicals like superoxide and nitric oxide [1] [2] [3]. However, production of IFN- $\gamma$ in turn is regulated by another pro-inflammatory cytokine interleukin 12 (IL-12), also secreted by monocytes/macrophages [4] [5] [6]. In our earlier study on an asymptomatic group of blood donors with human immunodeficiency virus type-1 (HIV-1) infection, the subgroup with history of oral iron intake was found to develop high incidence of pulmonary tuberculosis (PT) on follow up resulting in rapid progression to death, a finding that was considered to be related to deficiency of serum level of IFN- $\gamma$ detected during early asymptomatic stage of HIV-I infection although status of IL-12 was not evaluated [7]. Studies have shown that effective defense against $M$. tuberculosis requires contribution of additional pro-inflammatory cytokines such as interleukin-1 beta (IL-1 $\beta$ ), interleukin-6 (IL-6) and interleukin-8 (IL-8) [8] [9] [10].

Timely recognition of defects in immunity against $M$. tuberculosis would be of greater relevance at early asymptomatic stage of HIV-1 infection when prophylactic measure against infection due to this agent can be planned. Present report is an extension of the previous report [7] to provide information on serum levels of IL-12p70 (bioactive heterodimeric form of IL-12 in serum) and additional pro-inflammatory cytokines viz. IL- $1 \beta$, IL- 6 and IL-8 along with the status of production of nitric oxide (NO) measured as nitrite, superoxide anion and IL-12p70 by monocyte derived macrophages (MDMs) at asymptomatic stage as well as at the time of development of PT on follow up in HIV-1 infected blood donors in relation to history of oral iron intake.

\section{Materials and Methods}

\subsection{Study Subjects}

The details of characterization of subjects included in the present study have been described earlier [7]. Briefly, the study subjects included a group of male remunerated blood donors between 24 - 34 years with asymptomatic HIV-1 infection enrolled during 1992-1996 (a period before the introduction of legal ban on remunerated blood donation in the country) $(\mathrm{n}=108)$ having positive $(\mathrm{n}=$ $54)$ or negative $(\mathrm{n}=54)$ history of oral iron consumption (subgroups I and II respectively). A group of HIV negative donors $(n=80)$ with positive $(n=30)$ or 
negative $(\mathrm{n}=50)$ for similar history (subgroups III and IV respectively), matched with HIV-1 positive donors in terms of age and sex were included. The study also included a group of age, sex and socio-economically matched healthy community controls $(\mathrm{n}=40)$ without any history of blood donation (subgroup $\mathrm{V}$ ). The ethical clearance of institutional review board and informed consent from the study subjects, were obtained as per standard protocol. Only those HIV-1 positive donors with clinically asymptomatic status, unimpaired blood CD4+ T lymphocyte counts i.e. $\geq 500$ cells/cu $\mathrm{mm}$, normal values in renal and thyroid function tests were included in the same study. All the donors and community controls were screened to exclude sero-positivity for HBV, HCV and Syphilis at enrolment and periodically during the study.

The various subgroups of donors were followed up for development of any AIDS related illness (ARI, stage III) based on WHO criteria [11]. The protocol of follow up for detection of ARI and categorization of ARI into pulmonary tuberculosis (PT) and categories of ARI other than PT (non-PT) has been described earlier [7].

Blood sample was collected in plain sterile tube to yield serum for estimation of cytokines, nitrite, citrulline and neopterin levels while heparinized blood sample was used for culture of monocytes to yield monocyte derived macrophages (MDMs). Only those HIV-1 seropositive donors from whom blood samples could be collected both at enrolment and at the time of development of ARI were included for analysis of laboratory parameters.

\subsection{Estimation of Serum Levels of Cytokines}

Measurement of levels of pro-inflammatory cytokines viz. IL-1 $\beta$, IL-6, IL-8 and IL-12p70 in serum was carried out employing commercial reagents and kits (Quantikine, R\&D Systems, Minneapolis, USA) with sensitivity levels as $1 \mathrm{pg} / \mathrm{ml}$, $0.70 \mathrm{pg} / \mathrm{ml}, 3.5 \mathrm{pg} / \mathrm{ml}$ and $0.5 \mathrm{pg} / \mathrm{ml}$ respectively. The co-efficient of variation was detected to be less than $10 \%$ for all the kits and specificity of the kits was crosschecked using heterogeneous recombinant cytokines. Serum sample showing undetectable level of cytokine was ascribed $0 \mathrm{pg} / \mathrm{ml}$ value for the purpose of present study.

\subsection{Estimation of Serum Levels of Nitrite, Citrulline and Neopterin}

Estimation of serum levels of nitrite, which is the stable product of nitric oxide (half-life of nitric oxide 5-6 sec), was based on Griess reaction [12]. Briefly, serum sample was diluted four fold in distilled water and deproteinised by adding zinc sulfate (final concentration $15 \mathrm{~g} / \mathrm{L}$ ) followed by centrifugation at $10,000 \mathrm{~g}$ for 5 minutes at room temperature. One hundred microliter of supernatant as well as $100 \mu \mathrm{l}$ of varying dilutions of nitrite standards (Sigma Chemicals, USA) were charged in flat bottom 96 well plate. One hundred microliter of Greiss reagent $(0.1 \%$ naphthalene-diamine-dihydrochloride, $1 \%$ sulphanilamide and $2.5 \%$ 
phosphoric acid) was added to each well. The plate was incubated for 10 minutes at room temperature in dark and was read at $550 \mathrm{~nm}$ in an automated plate reader (Multiskan, Lab systems). Quantity of nitrite in samples was calculated from absorbance values plotted against the standard curve obtained from the values of the serial dilutions of nitrite standards using reading of the reaction mixture without serum as blank. Each sample was run in triplicate and average value was taken. The lower limit of detection of nitrite concentration in serum was $250 \mathrm{nM}$.

Estimation of serum citrulline level as the surrogate marker to validate production of nitric oxide through arginine utilization pathway was carried out by colorimetric method based on the protocol described by Boyde and Rahmatulla [13]. Briefly, serum sample was deproteinized by adding tricarboxylic acid solution (final concentration 5\%) followed by centrifugation. Chromogenic reagent was prepared just before use by adding $5 \mathrm{mg}$ thiosemicarbazide (Sigma Chemicals, USA) to $50 \mathrm{ml}$ of $0.5 \%$ diacetyl-monoxime (Sigma Chemicals, USA) solution followed by addition of $100 \mathrm{ml}$ of acid-ferric solution prepared by dissolving $\mathrm{FeCl}_{3}(25 \mathrm{mg}$ ) in $100 \mathrm{ml}$ solution containing $25 \mathrm{ml}$ concentrated sulphuric acid (95\% - 98\%), $20 \mathrm{ml}$ concentrated phosphoric acid (85\%) and $55 \mathrm{ml}$ distilled water. To $100 \mu \mathrm{l}$ of supernatant, $3 \mathrm{ml}$ of chromogenic solution was added, mixed vigorously and boiled at $100^{\circ} \mathrm{C}$ for 5 minutes. Enzyme urease (Type VII, Sigma Chemicals, USA) was included in the mixture to prevent formation of colour complex by urea with diacetyl-monoxime. The tubes were cooled to room temperature and absorbance was measured at $530 \mathrm{~nm}$ in a spectrophotometer. Quantity of citrulline in supernatant was calculated from a standard curve of absorbance values prepared by running varying dilutions of DL-citrulline (Sigma Chemicals, USA) simultaneously with samples. Representative samples (40\%) were also analyzed by high performance liquid chromatography (HPLC) (Shimadzu Corporation, Japan) to validate detection levels by the colorimetric assay ( $<5 \%$ variation). The detection limit of citrulline was $2.5 \mu \mathrm{M} / \mathrm{L}$. Serum neopterin level, as a measure of activation of mononuclear phagocytes, was determined by HPLC system (Shimadzu Corporation, Japan) using ultra filtered serum with limit of detection as $0.7 \mathrm{nmol}$.

\section{Detection of Nitrite, Citrulline, Neopterin, Superoxide and IL-12p70 Produced by MDMs}

\subsection{Reagents Used}

The L-arginine, $\mathrm{N}^{G}$ monomethyl-L-Arginine ( $\left.\mathrm{N}^{G} \mathrm{MMA}\right)$, lipopolysaccharide (LPS, E. coli derived), phorbol myristate acetate (PMA), cytochrome C (type III) and superoxide dismutase (SOD) were all obtained from Sigma Chemical, USA while recombinant IFN- $\gamma(\mathrm{rFN}-\gamma)$ (sp. activity $10^{7} \mathrm{IU} / \mathrm{mg}$ of protein) was obtained from Boeheringer Mannheim, Germany. Staphylococcus aureus Cowan (SAC) strain was utilized from lyophilized laboratory stock at a final concentration of $0.01 \%$. 


\subsection{Isolation and Culture of Monocytes for Production of MDMs}

Mononuclear cells were isolated from peripheral blood by layering on Ficoll hypaque (specific gravity 1.077) followed by density gradient centrifugation at 400 $\mathrm{g}$ for 30 minutes at $22^{\circ} \mathrm{C}$. Interphase cells were recovered, washed in Hanks balanced salt solution (HBSS) and re-suspended in Iscove's modified Dulbecco's medium (IMDM, Sigma Chemicals, USA) with $25 \%$ heat inactivated human serum supplemented with Gentamycin Sulfate $(40 \mu \mathrm{g} / \mathrm{ml})$ and Amphotericin B $(0.25 \mu \mathrm{g} / \mathrm{ml})$. The endotoxin content of the medium, as tested by Limulus lysate assay, was negligible $(<0.1 \mathrm{ng} / \mathrm{ml})$. Approximately $3 \times 10^{6}$ cells $/ \mathrm{ml}$ were plated in 24 well culture plates and allowed to adhere to the wells at $37^{\circ} \mathrm{C}$ in $5 \% \mathrm{CO}_{2}$ atmosphere. The supernatant medium and non-adherent cells were washed away at $4 \mathrm{~h}$ and $24 \mathrm{~h}$ with replacement of medium following which adherent cells were removed from the plate by gentle scraping with a plastic scraper and resuspended in medium. The resuspended cells were found to contain $>95 \%$ monocytes as evident by microscopy and by flow cytometric analysis (EPICS profile version II, Coulter, Hialeah, Fl) using labeled monoclonal antibodies (Beckton Dickinson) with monocytes showing negative expression for CD3 and CD19 but positive for CD14. Viability of the monocytes was checked by trypan blue exclusion. Platelet contamination was limited to $1-4$ platelets per monocyte. The monocytes $\left(10^{6}\right.$ cells $\left./ \mathrm{ml}\right)$ were cultured in 96 well microtiter plates and allowed to differentiate into MDMs progressively upto 7 days in a $5 \% \mathrm{CO}_{2}$ atmosphere at $37^{\circ} \mathrm{C}$ with intermittent removal of media containing the non-adherent cells by aspiration and replenishment of fresh culture medium. Microbial contamination of culture was excluded by demonstration of negative bacterial growth in culture of supernatants on blood and chocolate agar plates.

\subsection{Detection of Nitrite, Citrulline, Neopterin, IL-12p70 and Superoxide Produced by MDM Culture}

A set of two microtiter plates $(12 \times 8$ well format $)$ was used in the study, one for production of nitrite, citrulline, neopterin, IL-12p70 and the second for production of superoxide by MDM culture.

1) Detection of nitrite, citrulline, neopterin, IL-12p70 produced by MDM culture

The optimum protocol for studying the production of nitrite, citrulline, neopterin and IL-12p70 by MDMs in response to challenge with various stimulants was broadly based on the one described earlier [14]. Briefly, in each row of the first microtiter plate, four pairs of wells were seeded with $200 \mu \mathrm{l}$ of MDM suspension $\left(10^{6} / \mathrm{ml}\right)$ from each sample, out of which three pairs of wells were identified for challenging with three stimulants, one pair/stimulant, while the fourth pair of wells was identified for cell control without any stimulant. An additional fifth pair of wells in the same row without MDM received only IMDM medium to serve as medium control. The first pair of wells was challenged with LPS (1 $\mu \mathrm{g} / \mathrm{ml}$ ) to study generation of nitrite, citrulline and neopterin while the second and third pairs were challenged with PMA and SAC respectively to study gener- 
ation of IL-12p70. Twenty four hour prior to challenge with stimulants, first well in each pair with MDM culture was treated with $\operatorname{rIFN}-\gamma(100 \mathrm{IU} / \mathrm{ml})$ to provide priming effect on the MDMs while the second well in each pair did not receive any rIFN- $\gamma$. The plate was incubated at $37^{\circ} \mathrm{C}$ in $5 \% \mathrm{CO}_{2}$ atmosphere following which the supernatants from each well was collected and subjected to estimation of nitrite, citrulline, and neopterin from first pair of wells and IL-12p70 from second and third pair of wells challenged with PMA (10 ng/ml) and SAC $(0.01 \%$ w/v) respectively. The cell control and medium control wells were also checked for spontaneous production of the analytes. In case of first pair of wells, challenged with LPS with or without priming by rIFN- $\gamma$, two additional days of incubation was extended as follows. L-Arginine $(200 \mu \mathrm{mol})$ was added to the MDM culture immediately following withdrawal of supernatant and incubation was carried out for another $24 \mathrm{~h}$ to study the stimulatory effect of L-Arginine on nitrite production through Arginine dependent pathway. The culture of MDMs in the same pair of wells was then subjected to addition of $\mathrm{N}^{\mathrm{G}} \mathrm{MMA}(1 \mathrm{mmol})$ and incubation was further extended for another $24 \mathrm{~h}$ to study the effect of $\mathrm{N}^{\mathrm{G}} \mathrm{MMA}$, known to reverse the effect of L-Arginine on production of NO [14].

Estimation of nitrite from supernatant was carried out following the same protocol as that employed for serum except the step of deproteinisation. The results were expressed as nmols of $\mathrm{NO}_{2}$ produced/well. Content of citrulline and neopterin in culture supernatant were quantitated by autoanalyzer. Sample showing undetectable levels of nitrite or citrulline was regarded as 0 for simplification of analysis [15].

Supernatants from second and third pair of wells, stimulated by PMA or SAC respectively were collected for estimation of IL-12p70 by ELISA using reagents from commercial sources (R\&D systems, USA) [16]. Briefly, a 96 well polystyrene plate was coated with mouse anti-human IL-12p70 monoclonal antibodies diluted in PBS and incubated at $4^{\circ} \mathrm{C}$ overnight. The plate was then washed thoroughly with PBS containing $0.1 \%$ tween 20 and blocked with $200 \mu \mathrm{l}$ of $10 \%$ skimmed milk for $2 \mathrm{~h}$ at room temperature. Varying concentrations of human recombinant IL-12p70 standards were prepared in PBS containing 0.1\% tween 20 and $1 \%$ non-fat milk. One hundred microliter of supernatant each from both primed and unprimed MDM cultures stimulated with PMA or with SAC along with the standards were added to the wells and the plate was incubated at $4^{\circ} \mathrm{C}$ overnight. Following incubation the plate was washed thoroughly with PBS containing tween 20 and $100 \mu \mathrm{l}$ of biotinylated goat antihuman IL-12 (polyclonal, concentration $30 \mu \mathrm{g} / 100 \mu \mathrm{l}$ ) was added to each well. The plate was incubated at $37^{\circ} \mathrm{C}$ for $1 \mathrm{~h}$ followed by washing 4 times. One hundred microliter of streptavidin-HRP conjugate ( 1 in 4000 dilution) was added in each microwell and incubated at $37^{\circ} \mathrm{C}$ for $30 \mathrm{~min}$ followed by washing 3 times. Freshly prepared tetramethylbenzidine and hydrogen peroxide mixture was added as substrate, incubated for $20 \mathrm{~min}$ in dark and reaction was stopped by addition of $50 \mu \mathrm{l}$ of $2 \mathrm{~N}$ $\mathrm{H}_{2} \mathrm{SO}_{4}$. The plate was read in a microplate reader (Multiskan, Labsystems) at 450 
$\mathrm{nm}$. The recorded OD value was converted into concentration by matching with the reference graph of the OD values of the standards. The detection limit of IL-12p70 was determined as $1 \mathrm{pg} / \mathrm{ml}$. Cross reactivity of the plates for other cytokines (e.g. IL-1, IL-2, IL-4 and TNF- $\alpha$ ) was detected to be negligible while intra-assay and inter-assay variation was found to be $<10 \%$.

2) Detection of superoxide produced by MDM culture

The second microtiter plate was used to study superoxide production by demonstration of superoxide dismutase (SOD)-inhibitable reduction of ferricytochrome C [17]. Three pairs of wells were used per sample, out of which the first pair contained MDMs to be challenged with LPS $(1 \mu \mathrm{g} / \mathrm{ml})$ with or without priming by IFN- $\gamma$, the second pair contained MDMs without any challenge with stimulant to serve as cell control while the third pair contained medium only to serve as medium control. The plate was incubated under identical condition and duration as described for the first plate. Before the assay, the medium in the MDM culture was removed from the wells by aspiration and replaced with $1 \mathrm{ml}$ of HBSS and the cells were allowed to stabilize for $15 \mathrm{~min}$ at $37^{\circ} \mathrm{C}$ before being challenged with a mixture containing $80 \mu \mathrm{M}$ ferricytochrome C type III (Sigma Chemicals, USA) in HBSS, pH 7.4 and PMA (100 ng/ ml). The microtiter plate was incubated at $37^{\circ} \mathrm{C}$ in $5 \% \mathrm{CO}_{2}$ for 90 minute followed by measurement of absorbance at $550 \mathrm{~nm}$. The medium in the cell control well was removed and layered with $100 \mu \mathrm{l}$ of ferri-cytochrome C supplemented with SOD $(30 \mu \mathrm{g} / \mathrm{ml}$, Sigma chemicals, USA) as a quality check to ensure specificity of superoxide production through SOD-inhibitable cytochrome reduction. The medium control well was checked for spontaneous production of superoxide. Culture medium was also tested for interfering SOD activity by measurement of its ability to inhibit the superoxide production in a superoxide generating system (data not shown). Results were converted to nmol of cytochrome reduced using extinction co-efficient as $21 \mathrm{mM}^{-1} \mathrm{~cm}^{-1}$. Triton $\mathrm{X}(1 \%)$ was added to each well and protein assay was conducted using Lowry method with bovine serum albumin as standard [18]. Results were expressed as nmol of superoxide anion produced/mg of cell protein/minute.

\section{Statistical Analysis}

Analysis of various parameters in HIV-1 positive subgroups (subgroup I and II) was undertaken both at enrolment as well as at the point of development of ARI. In the HIV negative subgroups of donors (subgroups III and IV) as well as in HIV negative non-donor community controls (subgroup V), only enrolment samples were included for comparison since no individual in these subgroups developed ARI on follow up.

Comparison of various immunological parameters at enrolment as well as at the time of development of ARI (PT or non-PT) was made by one-way ANOVA followed by positive test with Bonferroni multiple comparisons for continuous variables with normal distribution characteristics. Continuous variables not fol- 
lowing normal distribution were compared by Kruskal Wallis test followed by multiple comparisons using Mann-Whitney test with Bonferroni adjustment. P value $<0.05$ was taken as statistically significant and it was adjusted for multiple comparison wherever applicable. Correlation of continuous variables with normal distribution was carried out by Pearson's correlation test.

\section{Results}

\subsection{Incidence of ARI}

Details of the incidence and category of ARI in various subgroups of donors in relation to history of oral iron intake have been described in the earlier study [7]. Briefly, the subgroups of HIV-1 positive donors, with history of iron intake (subgroup I) developed PT and non-PT category of ARI in 70.4\% (38 out of 54) and $29.6 \%$ (16 out of 54) patients respectively on follow up while in the non-iron consuming subgroup of donors (subgroup II) $18.5 \%$ (10 out of 54 ) and $81.5 \%$ (44 out of 54) developed PT and non-PT category of ARI respectively. Among the 30 cases in subgroup III, only 4 (13.3\%) developed PT on follow up while none of the donors in subgroup IV and community controls (subgroup V) developed any illness indicative of ARI on follow up. In the same study the subgroups of blood donors with history of oral iron intake i.e. subgroups I and III had shown significantly higher levels of iron parameters in blood compared to subgroups without history of iron intake i.e. subgroups II and IV that had levels comparable to controls. These findings and the probable mechanism of such high blood iron levels in the iron consuming subgroups was considered to be a reflection of oral iron intake in excess to the physiological requirement [7].

\subsection{Serum Levels of Pro-Inflammatory Cytokines}

Study of the pro-inflammatory cytokines in serum at enrolment in subgroup I donors showed levels of IL- $1 \beta$, IL- 6 and IL- 8 to be elevated among cases that developed PT category of ARI, while their levels were comparable to control group among cases developing non-PT category of ARI. Enrolment levels of these cytokines in serum among the subgroup II of HIV-1 positive donors were comparable to control group regardless whether they developed PT or non-PT category of ARI. Re-assessment of these cytokines at the point of development of ARI in the two subgroups of donors showed continued elevation of their levels at the point of development of PT compared to enrolment levels without any change at the point of development of non-PT category of ARI in subgroup I. Similar assessment in subgroup II donors continued to show unaltered levels compared to that of enrolment levels regardless of category of ARI developed i.e. PT or non-PT. Serum levels of IL-12p70 at enrolment was found to be depressed among cases developing PT as well as those developing non-PT category of ARI in both the subgroups I and II although the extent of such depression was more marked in cases developing PT category of ARI compared to non-PT category of ARI in both the subgroups. At the point of development of ARI both subgroups 
I and II showed some improvement in IL-12p70 level in PT as well as in non-PT category of cases although their levels remained still significantly lower compared to control values. The subgroup III donors showed elevated levels of the three pro-inflammatory cytokines i.e. IL-1 $\beta$, IL-6 and IL- 8 and depressed level of IL-12p70 compared to community controls at enrolment. The pattern of such alterations was comparable to the enrolment levels shown by cases in subgroup I that developed PT. The subgroup IV donors showed levels of these cytokines comparable to controls (Table 1).

\subsection{Serum Levels of Nitrite, Citrulline and Neopterin}

There was significant depression of nitrite, citrulline and neopterin levels in serum at enrolment in subgroup I of HIV-1 positive donors, more marked in those cases that developed PT compared to those developing non-PT category of ARI. On the contrary, in subgroup II there was significant increase in the levels of these parameters at enrolment, more marked in those cases that developed PT compared to those developing non-PT category of ARI (Table 2).

At the point of development of ARI on follow up, cases in both subgroups I and II showed significant elevation of nitrite, citrulline and neopterin levels in serum regardless of category of ARI. The subgroup III donors showed depression of nitrite, citrulline and neopterin levels at enrolment similar to subgroup I

Table 1. Serum level (Mean \pm SD) of pro-inflammatory cytokines in various subgroups of blood donors at enrolment and at follow up in relation to category of ARI developed.

\begin{tabular}{|c|c|c|c|c|c|c|c|c|}
\hline \multirow{3}{*}{ Cytokines } & \multirow{3}{*}{$\begin{array}{c}\text { Assessment } \\
\text { point }\end{array}$} & \multicolumn{4}{|c|}{ HIV-1 positive } & \multicolumn{2}{|c|}{ HIV negative } & \multirow{2}{*}{$\begin{array}{c}\text { Community } \\
\text { controls }\end{array}$} \\
\hline & & \multicolumn{2}{|c|}{$\begin{array}{l}\text { Fe pos }(\text { Sgr I }) \\
\mathrm{n}=54\end{array}$} & \multicolumn{2}{|c|}{$\begin{array}{l}\text { Fe neg (Sgr II) } \\
\mathrm{n}=54\end{array}$} & $\begin{array}{l}\text { Fe pos } \\
\text { (Sgr III) }\end{array}$ & $\begin{array}{l}\text { Fe neg } \\
\text { (Sgr IV) }\end{array}$ & \\
\hline & & \multicolumn{2}{|c|}{$\begin{array}{l}\text { Category of ARI on } \\
\text { follow up }\end{array}$} & \multicolumn{2}{|c|}{ Category of ARI on follow up } & & & \\
\hline \multirow{2}{*}{$\mathrm{IL}-1 \beta(\mathrm{pg} / \mathrm{ml})$} & En & $67 \pm 18.6^{\# \S}$ & $19 \pm 8.6$ & $21 \pm 11.4$ & $19 \pm 14.8$ & $58 \pm 22.6^{\#}$ & $14 \pm 11.4$ & $17 \pm 12.2$ \\
\hline & $\mathrm{Fu}$ & $102 \pm 28.5^{\star}$ & $21 \pm 10.5$ & $26 \pm 6.7$ & $18 \pm 8.6$ & NA & NA & NA \\
\hline IL-6 (pg/ml) & En & $102 \pm 32.4^{\# \S}$ & $47 \pm 18.2$ & $49 \pm 24.2$ & $39 \pm 13.9$ & $90 \pm 31.4^{\#}$ & $40 \pm 20.8$ & $42 \pm 22.6$ \\
\hline \multirow{2}{*}{$\mathrm{IL}-8(\mathrm{pg} / \mathrm{ml})$} & En & $165 \pm 40.4^{\# \S}$ & $92 \pm 28.4$ & $88 \pm 28.8$ & $81 \pm 20.5$ & $147 \pm 32.2^{\#}$ & $73 \pm 28.4$ & $85 \pm 32.4$ \\
\hline & $\mathrm{Fu}$ & $263 \pm 27.3^{\star}$ & $96 \pm 32.5$ & $100 \pm 34.9$ & $88 \pm 27.4$ & NA & NA & NA \\
\hline \multirow{2}{*}{$\begin{array}{l}\text { IL-12p70 } \\
(\mathrm{pg} / \mathrm{ml})\end{array}$} & En & $3.8 \pm 3.5^{p_{\ddagger}}$ & $8.4 \pm 4.6^{p}$ & $9.4 \pm 4.6^{p_{t}}$ & $16.6 \pm 6.9^{p}$ & $6.9 \pm 3.2^{p}$ & $32.4 \pm 16.8$ & $42.4 \pm 18.6$ \\
\hline & $\mathrm{Fu}$ & $12.4 \pm 4.2^{\star}$ & $16.1 \pm 5.6^{*}$ & $20.4 \pm 4.9^{*}$ & $24.8 \pm 5.7^{\star}$ & NA & NA & NA \\
\hline
\end{tabular}

1) Sgr I-V = Subgroups I-V; En = Enrolment, Fu = Follow up (at the point of development of ARI); PT = Pulmonary tuberculosis; non-PT = Category of ARI other than PT; Fe pos and Fe neg = Blood donors with positive and negative history of oral iron intake; NA = Not applicable. 2) Statistical comparisons (using multiple comparisons with level of significance at $\mathrm{p}<0.05$ ). "Significant elevation vs. Community controls (Sgr V); ${ }^{\circledR}$ Significant elevation, PT vs.

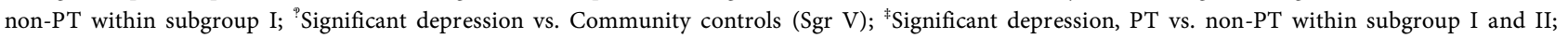
*Significant elevation in level at the point of development of ARI on follow up compared to that of enrolment for the same category of analyte in corresponding subgroup of blood donors. 
Table 2. Serum levels (Mean \pm SD) of nitrite, citrulline and neopterin in various subgroups of blood donors at enrolment and at follow up in relation to category of ARI developed.

\begin{tabular}{|c|c|c|c|c|c|c|c|c|}
\hline \multirow{4}{*}{$\begin{array}{l}\text { Marker of } \\
\text { nitric oxide } \\
\text { production }\end{array}$} & \multirow{4}{*}{$\begin{array}{l}\text { Assessment } \\
\text { point }\end{array}$} & \multicolumn{4}{|c|}{ HIV-1 positive } & \multicolumn{2}{|c|}{ HIV negative } & \multirow{2}{*}{$\begin{array}{c}\text { Community } \\
\text { controls } \\
(\text { Sgr V) }\end{array}$} \\
\hline & & \multicolumn{2}{|c|}{$\begin{array}{l}\text { Fe pos (Sgr I) } \\
\mathrm{n}=54\end{array}$} & \multicolumn{2}{|c|}{$\begin{array}{l}\text { Fe neg (Sgr II) } \\
\mathrm{n}=54\end{array}$} & $\begin{array}{c}\text { Fe pos } \\
\text { (Sgr III) }\end{array}$ & $\begin{array}{l}\text { Fe neg } \\
(\text { Sgr IV) }\end{array}$ & \\
\hline & & \multicolumn{2}{|c|}{$\begin{array}{l}\text { Category of ARI on } \\
\text { follow up }\end{array}$} & \multicolumn{2}{|c|}{ Category of ARI on follow up } & & & \\
\hline & & $\begin{array}{l}\mathrm{PT} \\
\mathrm{n}=38\end{array}$ & $\begin{array}{c}\text { non-PT } \\
\mathrm{n}=16\end{array}$ & $\begin{array}{l}\text { PT } \\
\mathrm{n}=10\end{array}$ & $\begin{array}{c}\text { non-PT } \\
\mathrm{n}=44\end{array}$ & $\mathrm{n}=30$ & $\mathrm{n}=50$ & $\mathrm{n}=40$ \\
\hline \multirow{2}{*}{ Nitrite $(\mu \mathrm{M})$} & En & $1.1 \pm 0.6^{p \ddagger}$ & $2.6 \pm 0.4^{p}$ & $20.2 \pm 6.6^{\# \S}$ & $12.8 \pm 3.5^{\#}$ & $1.3 \pm 0.8^{p}$ & $5.2 \pm 3.8$ & $4.4 \pm 2.6$ \\
\hline & $\mathrm{Fu}$ & $56.6 \pm 16.2^{\star}$ & $32.8 \pm 13.5^{\star}$ & $36.4 \pm 10.8^{\star}$ & $22.4 \pm 5.6^{*}$ & NA & NA & NA \\
\hline \multirow{2}{*}{ Citrulline $(\mu \mathrm{M})$} & En & $4.2 \pm 2.1^{\text {P‡ }}$ & $8.2 \pm 2.6^{p}$ & $46.2 \pm 19.6^{\# \S}$ & $31.8 \pm 12.4^{\#}$ & $5.2 \pm 3.1^{\mathrm{p}}$ & $24 \pm 7.4$ & $20 \pm 8.6$ \\
\hline & $\mathrm{Fu}$ & $82.4 \pm 10.6^{\star}$ & $56.6 \pm 12.4^{*}$ & $60.4 \pm 8.2^{*}$ & $52.4 \pm 8.2^{\star}$ & NA & NA & NA \\
\hline \multirow{2}{*}{ Neopterin (nM) } & En & $0.8 \pm 0.3^{P_{\ddagger}}$ & $1.2 \pm 0.6^{p}$ & $22.4 \pm 3.4^{\# \S}$ & $12.1 \pm 5.2^{\#}$ & $0.9 \pm 0.24^{\text {p }}$ & $2.6 \pm 2.4$ & $6.8 \pm 3.4$ \\
\hline & $\mathrm{Fu}$ & $19.4 \pm 6.6^{*}$ & $14.6 \pm 4.4^{\star}$ & $38.4 \pm 8.2^{\star}$ & $28.4 \pm 6.4^{*}$ & NA & NA & NA \\
\hline
\end{tabular}

1) Sgr I-V =Subgroups I-V; En=Enrolment, Fu = Follow up (at the point of development of ARI); PT = Pulmonary tuberculosis; non-PT = category of ARI other than PT; Fe pos and Fe neg = Blood donors with positive and negative history of oral iron intake; NA = Not applicable. 2) Statistical comparisons (using multiple comparisons with level of significance at $\mathrm{p}<0.05$ ). "Significant elevation vs. Community controls (Sgr V). ${ }^{\circledR}$ Significant elevation, PT vs. non-PT within subgroup II. PSignificant depression vs. Community controls (Sgr V). ${ }^{\ddagger}$ Significant depression, PT vs. non-PT within subgroup I. ${ }^{\star}$ Significant elevation in level at the point of development of ARI on follow up compared to that of enrolment for the same category of analyte in corresponding subgroup of blood donors.

enrolment levels, while the subgroup IV donors showed levels of nitrite, citrulline and neopterin comparable to controls (Table 2).

\subsection{Production of Nitrite, Citrulline and Neopterin by MDMs}

Estimation of nitrite as indicator of nitric oxide production by MDM culture in subgroup I revealed significant depression at enrolment in cases developing PT as well as those developing non-PT category of ARI, more marked among former cases compared to later without any effect of priming of MDMs by rIFN- $\gamma$. On the other hand, the subgroup II donors showed increased production of nitrite by MDM culture at enrolment in both categories i.e. those developing PT as well as those developing non-PT ARI with significant augmentation by rIFN- $\gamma$ priming (Table 3).

However at the point of development of ARI, subgroup I donors showed reversal in the pattern of production of nitrite by MDMs in comparison to enrolment status demonstrating increased production in both categories of ARI, more in PT compared to non-PT category, with significant augmenting effect shown by rIFN- $\gamma$ priming of MDMs. At similar point i.e. at follow up, both PT and non-PT category of cases in subgroup II continued to show comparably higher level of nitrite production by MDMs with augmenting effect by rIFN- $\gamma$ priming. The subgroup III donors showed significantly depressed pattern of nitrite production by MDMs at enrolment similar to subgroup I enrolment levels without any effect of rIFN- $\gamma$ priming, while the subgroup IV donors showed production of nitrite comparable to controls with augmentation in levels induced by rIFN- $\gamma$ 
Table 3. Levels (Mean \pm SD) of nitrite and superoxide produced by LPS stimulated MDM culture, unprimed or primed by rIFN- $\gamma$, in various subgroups of blood donors at enrolment and at follow up in relation to category of ARI.

\begin{tabular}{|c|c|c|c|c|c|c|c|c|c|}
\hline \multirow{4}{*}{ Parameters } & \multirow{4}{*}{$\begin{array}{l}\text { Assessment } \\
\text { point }\end{array}$} & \multirow{4}{*}{$\begin{array}{l}\text { Status of } \\
\text { priming }\end{array}$} & \multicolumn{4}{|c|}{ HIV-1 positive } & \multicolumn{2}{|c|}{ HIV negative } & \multirow{2}{*}{$\begin{array}{c}\text { Community } \\
\text { controls } \\
(\mathrm{Sgr} \mathrm{V})\end{array}$} \\
\hline & & & \multicolumn{2}{|c|}{$\begin{array}{l}\text { Fe pos (Sgr I) } \\
\mathrm{n}=54\end{array}$} & \multicolumn{2}{|c|}{$\begin{array}{l}\text { Fe neg (Sgr II) } \\
\mathrm{n}=54\end{array}$} & $\begin{array}{l}\text { Fe pos } \\
\text { (Sgr III) }\end{array}$ & $\begin{array}{l}\text { Fe neg } \\
(\text { Sgr IV) }\end{array}$ & \\
\hline & & & \multicolumn{2}{|c|}{$\begin{array}{l}\text { Category of ARI on } \\
\text { follow up }\end{array}$} & \multicolumn{2}{|c|}{ Category of ARI on follow up } & & & \\
\hline & & & $\begin{array}{l}\mathrm{PT} \\
\mathrm{n}=38\end{array}$ & $\begin{array}{c}\text { non-PT } \\
\mathrm{n}=16\end{array}$ & $\begin{array}{l}\text { PT } \\
\mathrm{n}=10\end{array}$ & $\begin{array}{c}\text { non-PT } \\
\mathrm{n}=44\end{array}$ & $\mathrm{n}=30$ & $\mathrm{n}=50$ & $\mathrm{n}=40$ \\
\hline \multirow{4}{*}{$\begin{array}{c}\text { Nitrite } \\
\text { (nmol/well) }\end{array}$} & \multirow[t]{2}{*}{ En } & Unpr & $0.31 \pm 0.20^{p \ddagger}$ & $0.62 \pm 0.32^{?}$ & $8.2 \pm 2.4^{\#}$ & $5.1 \pm 2.6^{\#}$ & $0.39 \pm 0.24^{?}$ & $3.1 \pm 0.8$ & $2.8 \pm 0.6$ \\
\hline & & $\operatorname{Pr}$ & $0.32 \pm 0.26$ & $0.58 \pm 0.32$ & $14.8 \pm 4.2^{\dagger}$ & $12.6 \pm 4.8^{\dagger}$ & $0.42 \pm 0.36$ & $10.2 \pm 4.8^{\dagger}$ & $8.4 \pm 2.6^{\dagger}$ \\
\hline & \multirow{2}{*}{$\mathrm{Fu}$} & Unpr & $18.2 \pm 2.4^{\# \text { S* }}$ & $9.1 \pm 1.9^{\# \star}$ & $10.6 \pm 2.8^{\#}$ & $6.8 \pm 3.6^{\#}$ & NA & NA & NA \\
\hline & & $\operatorname{Pr}$ & $42.8 \pm 8.2^{\Im}$ & $22.2 \pm 3.2^{\dagger \star}$ & $28.2 \pm 5.6^{\dagger *}$ & $26.2 \pm 4.6^{\dagger *}$ & NA & NA & NA \\
\hline \multirow{4}{*}{$\begin{array}{c}\text { Superoxide } \\
\text { (nmol/mg } \\
\text { protein/ } \\
\text { min) }\end{array}$} & \multirow{2}{*}{ En } & Unpr & $17.2 \pm 4.1^{\# \S}$ & $9.6 \pm 2.4^{\#}$ & $6.8 \pm 3.2$ & $5.8 \pm 3.4$ & $14.1 \pm 9.6^{\#}$ & $4.6 \pm 1.6$ & $4.1 \pm 1.8$ \\
\hline & & $\operatorname{Pr}$ & $18.6 \pm 3.2^{\S}$ & $10.2 \pm 4.2$ & $12.6 \pm 4.2^{\dagger}$ & $16.2 \pm 4.1^{\dagger}$ & $16.6 \pm 7.2$ & $6.3 \pm 2.6$ & $5.2 \pm 1.2^{\dagger}$ \\
\hline & \multirow{2}{*}{$\mathrm{Fu}$} & Unpr & $21.4 \pm 2.6^{\#}$ & $17.4 \pm 3.8^{\# \star}$ & $7.2 \pm 3.8^{\#}$ & $6.2 \pm 3.6$ & NA & NA & NA \\
\hline & & $\operatorname{Pr}$ & $48 \pm 8.4^{\dagger *}$ & $42 \pm 8.2^{\dagger \star}$ & $24.6 \pm 4.6^{\dagger \star}$ & $26.2 \pm 6.2^{\dagger \star}$ & NA & NA & NA \\
\hline
\end{tabular}

1) Sgr I-V = Subgroups I-V; En = Enrolment; Fu = At the point of development of ARI on follow up; PT = Pulmonary tuberculosis; non-PT = category of ARI other than PT; Fe pos and Fe neg = Blood donors with positive and negative history of oral iron intake Unpr = Unprimed MDMs; $\mathrm{Pr}=\mathrm{MDMs}$ primed

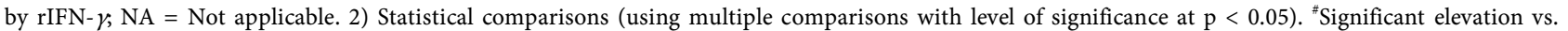
Community controls (Sgr V); ${ }^{\$}$ Significant elevation, PT vs. non-PT within subgroup I; 'Significant depression vs. Community controls (Sgr V); ${ }^{\sharp}$ Significant depression, PT vs. non-PT within subgroup I; ${ }^{\dagger}$ Significant augmentation in level on priming of MDMs by rIFN- $\gamma$; ${ }^{*}$ Significant elevation in level at the point of development of ARI on follow up compared to that of enrolment in the MDM cultures (i.e. primed by rIFN- $\gamma$ or unprimed) for the same category of analyte in corresponding subgroup of blood donors.

priming (Table 3). Levels of citrulline and neopterin produced by MDM culture primed or unprimed, followed the pattern of nitrite production in all the subgroups both at enrolment and at follow up (supplementary table). There was no measureable production of nitrite, citrulline or neopterine spontaneously by MDMs in culture in any category of cases in various subgroups even after priming by rIFN- $\gamma$ (data not shown). Exposure of MDMs in enrolment samples from various subgroups and controls with L-Arginine showed augmentation in levels of nitrite produced by MDMs, followed by lowering of levels on addition of $\mathrm{N}^{\mathrm{G}} \mathrm{MMA}$, regardless of whether primed or unprimed (Figure S1, Table S1).

\subsection{Production of Superoxide Anion by MDMs}

Assessment of levels of superoxide anions produced by cultured MDMs at enrolment in subgroup I demonstrated increased level, more marked in those who developed PT compared to those developing non-PT category of ARI, although these increased levels were not further augmented by pre-treatment of MDMs with rIFN- $\gamma$. Assessment of superoxide production by MDM at enrolment in subgroup II showed production comparable to controls. However, unlike subgroup I there was appreciable effect of rIFN- $\gamma$ priming towards boosting of levels recorded at enrolment in both categories regardless of the category of ARI developed (PT or non-PT) on follow up (Table 3). 
At the point of development of ARI, cases with PT as well as non-PT category of ARI in both subgroup I and subgroup II continued to show increased superoxide anion production with significant boosting effect by rIFN- $\gamma$ priming. The subgroup III donors demonstrated elevated level of superoxide production by MDM culture without any effect of priming by rIFN- $\gamma$ similar to subgroup I while subgroup IV showed levels comparable to controls. There was no evidence of spontaneous production of superoxide by MDMs in culture in any category of cases in various subgroups regardless of priming of MDMs by rIFN- $\gamma$ following stimulation (data not shown).

\subsection{Production of IL-12p70 by MDMs}

Production of IL-12p70 by MDMs in subgroup I, following stimulation by PMA, was depressed at enrolment in cases developing PT as well as to those developing non-PT category of ARI, the degree of such depression being more marked in the former category compared to later without any effect of priming by rIFN- $\gamma$ in either category. In the subgroup II, although some degree of depression could be recorded in the levels of IL-12p70 produced by MDMs at enrolment in the two categories of cases i.e. those developing PT as well as those developing non-PT category of ARI, but unlike the subgroup I both the categories showed enhancement in their levels upon pre-treatment of MDMs by rIFN- $\gamma$ (Table 4).

Table 4. Levels (Mean $\pm \mathrm{SD}$ ) of IL-12p70 (pg/ml) produced by MDM culture, unprimed or primed by rIFN- $\gamma$, upon stimulation by PMA or SAC in various subgroups of blood donors at enrolment and at follow up in relation to category of ARI developed.

\begin{tabular}{|c|c|c|c|c|c|c|c|c|c|}
\hline \multirow{4}{*}{ Stimulant } & \multirow{4}{*}{$\begin{array}{l}\text { Assessment } \\
\text { point }\end{array}$} & \multirow{4}{*}{$\begin{array}{l}\text { Status of } \\
\text { priming }\end{array}$} & \multicolumn{4}{|c|}{ HIV-1 positive } & \multicolumn{2}{|c|}{ HIV negative } & \multirow{2}{*}{$\begin{array}{c}\begin{array}{c}\text { Community } \\
\text { controls }\end{array} \\
(\text { Sgr V) }\end{array}$} \\
\hline & & & \multicolumn{2}{|c|}{$\begin{array}{l}\text { Fe pos }(\text { Sgr I }) \\
n=54\end{array}$} & \multicolumn{2}{|c|}{$\begin{array}{l}\text { Fe neg (Sgr II) } \\
\mathrm{n}=54\end{array}$} & $\begin{array}{l}\text { Fe pos } \\
\text { (Sgr III) }\end{array}$ & $\begin{array}{l}\text { Fe neg } \\
\text { (Sgr IV) }\end{array}$ & \\
\hline & & & \multicolumn{2}{|c|}{$\begin{array}{l}\text { Category of ARI on } \\
\text { follow up }\end{array}$} & \multicolumn{2}{|c|}{ Category of ARI on follow up } & & & \\
\hline & & & $\begin{array}{l}\mathrm{PT} \\
\mathrm{n}=38\end{array}$ & $\begin{array}{l}\text { non-PT } \\
\mathrm{n}=16\end{array}$ & $\begin{array}{l}\mathrm{PT} \\
\mathrm{n}=10\end{array}$ & $\begin{array}{l}\text { non-PT } \\
\mathrm{n}=44\end{array}$ & $\mathrm{n}=30$ & $\mathrm{n}=50$ & $\mathrm{n}=40$ \\
\hline \multirow{4}{*}{ PMA } & \multirow{2}{*}{ En } & Unpr & $1.2 \pm 2.0^{P_{\ddagger}}$ & $2.6 \pm 2.1^{p}$ & $2.4 \pm 0.9^{p}$ & $4.3 \pm 1.2^{?}$ & $1.6 \pm 1.4^{p}$ & $7.4 \pm 1.2$ & $8.6 \pm 1.8$ \\
\hline & & $\operatorname{Pr}$ & $1.6 \pm 1.8$ & $2.8 \pm 1.3$ & $10.4 \pm 4.8^{\dagger}$ & $12.2 \pm 6.8^{\dagger}$ & $1.8 \pm 1.4$ & $14.8 \pm 4.2^{\dagger}$ & $18.6 \pm 4.8^{\dagger}$ \\
\hline & \multirow{2}{*}{$\mathrm{Fu}$} & Unpr & $1.9 \pm 2.1^{p \neq}$ & $3.2 \pm 1.8^{p}$ & $3.2 \pm 1.2^{\mathrm{p}}$ & $4.4 \pm 0.8^{p}$ & NA & NA & NA \\
\hline & & $\operatorname{Pr}$ & $9.1 \pm 1.9^{\dagger^{*}}$ & $12.4 \pm 1.5^{\dagger^{*}}$ & $11.2 \pm 3.8^{\dagger}$ & $12.4 \pm 6.1^{\dagger}$ & NA & NA & NA \\
\hline \multirow{4}{*}{ SAC } & \multirow{2}{*}{ En } & Unpr & $4.8 \pm 2.6^{\varphi_{\ddagger}}$ & $8.4 \pm 4.2^{?}$ & $5.4 \pm 3.6^{p}$ & $7.8 \pm 4.2^{?}$ & $4.2 \pm 2.9^{p}$ & $72 \pm 32.4$ & $88 \pm 22.4$ \\
\hline & & $\operatorname{Pr}$ & $5.2 \pm 3.2$ & $9.6 \pm 5.1$ & $56 \pm 12.8^{\dagger}$ & $134 \pm 38.8^{\dagger}$ & $5.1 \pm 3.8$ & $134 \pm 42.6^{\dagger}$ & $148 \pm 32.6^{\dagger}$ \\
\hline & \multirow{2}{*}{$\mathrm{Fu}$} & Unpr & $7.2 \pm 3.6^{p}$ & $10.2 \pm 4.1^{p}$ & $8.6 \pm 4.2^{p}$ & $10.2 \pm 5.4^{?}$ & NA & NA & NA \\
\hline & & $\operatorname{Pr}$ & $58.8 \pm 20.2^{\dagger^{*}}$ & $78 \pm 16.2^{\dagger^{*}}$ & $68 \pm 12.8^{\dagger}$ & $144 \pm 18.2^{\dagger}$ & NA & NA & NA \\
\hline
\end{tabular}

1) Sgr I-V = Subgroups I-V; En = Enrolment; Fu = At the point of development of ARI on follow up; Unpr = Unprimed MDMs; Pr = MDMs primed by rIFN- $\gamma$, PT = Pulmonary tuberculosis; non-PT = category of ARI other than PT; Fe pos and Fe neg = Blood donors with positive and negative history of oral iron intake; NA = Not applicable. 2) Statistical comparisons (using multiple comparisons with level of significance at $\mathrm{p}<0.05$ ). ${ }^{\mathrm{P}}$ Significant depression vs. Community controls (Sgr V); ${ }^{*}$ Significant depression, PT vs. non-PT within subgroup I; ${ }^{\dagger}$ Significant augmentation in level on priming of MDMs by rIFN- $\gamma$, ${ }^{*}$ Significant elevation in level at the point of development of ARI on follow up compared to that of enrolment in the corresponding types of MDMs (i.e. primed by rIFN- $\gamma$ or unprimed) for the same category of analyte in corresponding subgroups of blood donors. 
At the point of development of ARI on follow up levels of IL-12p70 produced by PMA stimulated MDMs continued to remain lower compared to controls in both subgroups I and II but with significant boosting effect by rIFN- $\gamma$ priming in both categories of ARI i.e. PT and non-PT. The subgroup III donors demonstrated depression in the level of production of IL-12p70 by PMA stimulated MDMs, comparable to baseline levels showed in subgroup I without any priming effect of rIFN- $\gamma$ while the subgroup IV donors showed levels of IL-12p70 by MDMs unprimed or primed, comparable to controls.

Overall patterns of levels of IL-12p70 production by MDMs stimulated by SAC in various subgroups and categories of ARI were similar to the production of MDMs stimulated by PMA although the degree of changes was set at higher level in case of stimulation by SAC compared to PMA (Table 4).

\subsection{Correlation of Serum Ferritin Level and Production of Nitrite, Superoxide and IL-12p70 by MDMs at Enrolment in Iron Consuming Subgroup of HIV-1 Positive Donors (Subgroup I)}

It was observed that level of ferritin in serum at enrolment had significant negative correlation with levels of nitrite and IL-12p70 produced by MDM culture, regardless of stimulation by PMA or SAC and positive correlation with level of superoxide produced by MDM culture at same point of assessment (Figures 1(a)-(d)). The degree of such correlations were similar for both unprimed or primed MDMs $(\mathrm{r}=-0.52, \mathrm{p}<0.001$ and $\mathrm{r}=-0.45, \mathrm{p}=0.005$ for unprimed and primed MDMs respectively in case of nitrite (1a); $r=0.60, p=0.003$ and $r=$ $0.65, \mathrm{p}<0.001$ for unprimed and primed MDMs respectively in case of superoxide ( $1 \mathrm{~b}) ; \mathrm{r}=-0.45, \mathrm{p}=0.004$ and $\mathrm{r}=-0.51, \mathrm{p}=0.008$ for unprimed and primed MDMs respectively in case of IL-12p70 stimulated by PMA (1c); $r=$ $-0.56, \mathrm{p}=0.002$ and $\mathrm{r}=-0.57, \mathrm{p}=0.002$ for unprimed and primed MDMs respectively in case of IL-12p70 stimulated by SAC (1d).

\section{Discussion}

In the present study serum levels of all three pro-inflammatory cytokines viz. IL- $1 \beta$, IL-6 and IL- 8 were found to be elevated at baseline in HIV-1 positive blood donors with history of oral iron intake reflecting state of immune activation induced by high serum iron. These findings are in agreement with the elevated levels of immune activation markers i.e. TNF- $\alpha$, TNFR1 and TNFRII reported earlier in the same iron consuming subgroup of HIV-1 positive donors [7]. Co-infection with tuberculosis and HIV has been reported to lead to a synergistically heightened state of systemic immune activation and lung tissue damage [19] [20], which may support the finding of higher serum levels of pro-inflammatory cytokines recorded in PT cases compared to non-PT cases at the point of development of ARI among the HIV-1 positive donors with history of iron intake and may corroborate with shorter duration of post-PT survival compared to duration of survival following non-PT category of ARI observed in 


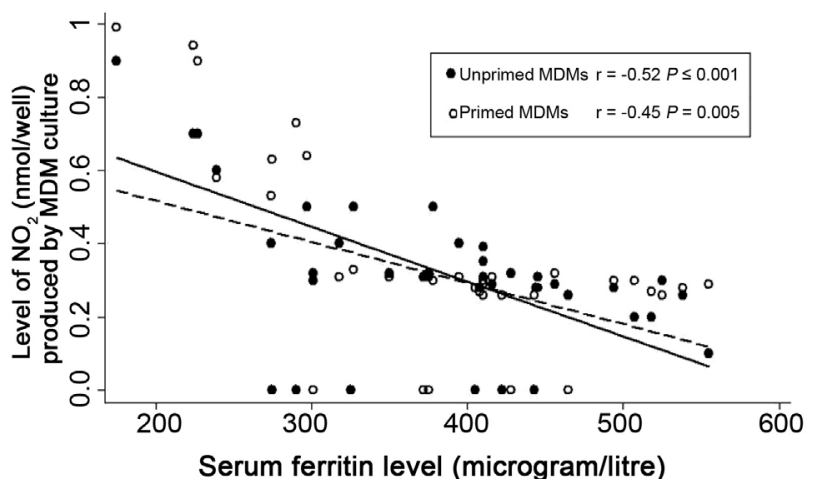

(a)

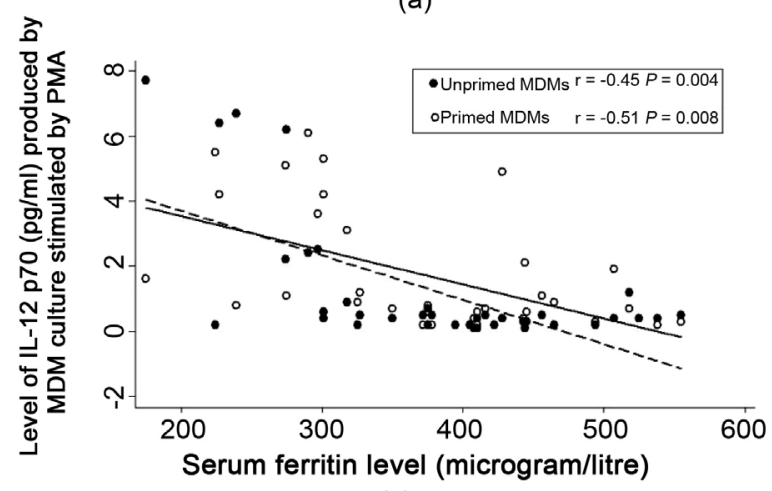

(c)

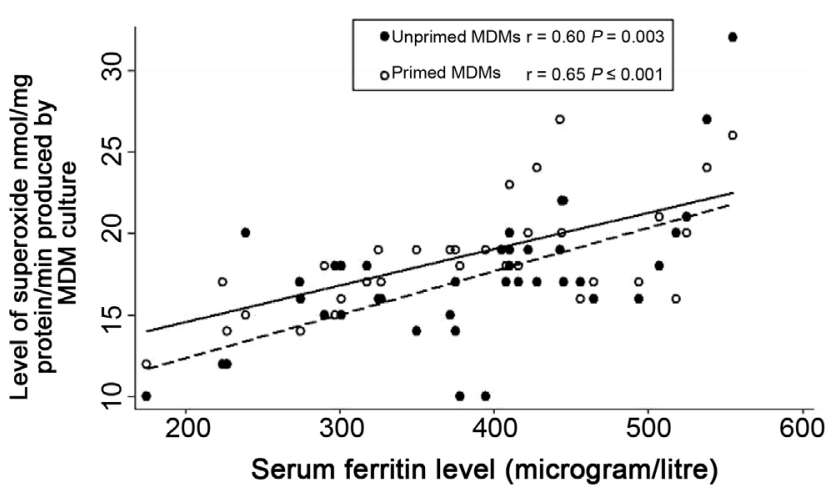

(b)

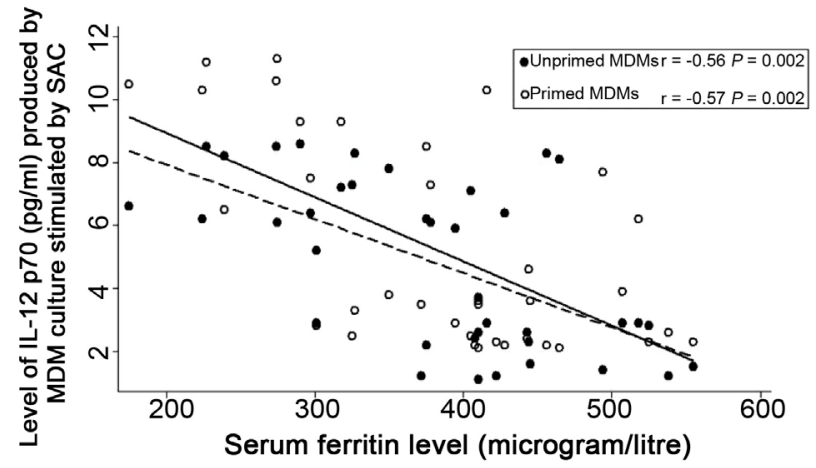

(d)

Figure 1. (a)-(d): Correlations between serum ferritin level and levels of (a) nitrite, (b) superoxide and (c) Level of IL-12p70 produced by PMA stimulated MDM culture and (d) level of IL-12p70 produced by MDM culture stimulated by SAC.

previous study [7].

In the present study pattern of changes in the levels of nitrite in serum among the iron consuming and non-iron consuming subgroups of HIV-1 positive donors correlated with that observed in MDM cultures in the corresponding subgroups suggesting the later as the possible source of former. HIV-1 infection, even at early stage, has been reported to be associated with increased nitrite production positively correlating with plasma and cell associated virus. HIV-1 protein e.g. Tat has been found to enhance transcription of iNOS by direct effect [21]. In the simian immune-deficiency virus/macaque model, significantly increased concentration of nitrite could be demonstrated in plasma during primary infection, co-incident with viraemia peaks even in the absence of opportunistic infections [22]. These reports corroborate with the finding of increased level of nitrite in the HIV-1 infected donors without any history of iron intake (subgroup II). On the contrary, nitrite level was found to be depressed in HIV-1 infected donors with history of iron intake (subgroup I) at enrolment regardless of whether they developed PT or non-PT category of ARI on follow up. Increased level of iron reduces the production of nitrite by preventing activation of the transcription factor Nuclear Factor Interleukin 6 (NF-IL-6) that regulates iNOS expression [23]. Depressed nitrite level in HIV-1 infected subgroup consuming oral iron could also be a result of enhanced Nuclear Factor Kappa Beta (NF-k $\beta$ ) production that is capable of binding to iNOS leading to decreased nitrite pro- 
duction [24]. It is likely that depressed nitrite production detected in subgroup I donors with increased serum iron overload reflected relatively more powerful inhibitory effect of iron on nitrite production than any stimulatory effect by HIV-1/HIV-1 proteins. However, considering the fact that among the subgroup I donors, those developing PT on follow up had significantly higher degree of depression of nitrite level at enrolment compared to those developing non-PT category of ARI on follow up and that over all incidence of PT in the same subgroup of donors was found to be higher compared to non-iron consuming subgroup of HIV-1 positive donors, it may be tempting to postulate that depressed nitrite production might have been responsible for greater susceptibility to M. tuberculosis due to impaired macrophage mediated defense in this subgroup.

Increased production of nitrite at the point of development of ARI in HIV-1infection, as observed in the present study, has also been observed by other workers [25]. Greater production of nitrite among PT cases in HIV-1 positive donors consuming iron compared to those without such practice may be related to shorter post -PT survival among former subgroup compared to later. It has been postulated that nitrite oxide (NO), the active unstable precursor of $\mathrm{NO}_{2}$ is produced in the lung during various processes like vascular regulation and as a consequence of host defense by various cell types like alveolar macrophages, bronchial and alveolar epithelial cells, endothelial cells and fibroblasts [26].

Nitrite measured in-vitro MDM culture is likely to be a true reflection of its production by cultured macrophage rather than contribution by non-macrophage components in tissue culture e.g. fetal calf serum [27] since the present study utilized surrogate markers of iNOS mediated pathway for NO production i.e. citrulline and neopterin, levels of both of which correlated with the levels of nitrite, substantiating specificity of the assay employed in the present study for NO production. In addition, significant augmentation and depression of nitrite level observed on addition of L-Arginine and $\mathrm{N}^{\mathrm{G}} \mathrm{MMA}$ respectively provides further support towards involvement of a specific Arginine mediated pathway of NO production [27].

Unlike inhibition of nitrite production observed among the iron-consuming category of HIV-1 positive donors in the present study, the same category of donors demonstrated marked increase in the level of superoxide anion in MDM culture. Increased level of reactive oxygen species (ROS) i.e. superoxide anion in HIV-1 infection is associated with other indications of oxidative stress conditions like reduction in glutathione [28]. Excess of iron facilitates and chelators prevent the generation of reactive oxygen species through inhibition of NADPH oxidase [29] [30]. While it is conceivable that increased incidence of M. tuberculosis in the iron consuming subgroup of HIV-1 infected donors may be related to impaired production of nitric oxide by macrophages as explained earlier, it may be apparently paradoxical to encounter increased superoxide production in the same subgroup which is considered instrumental in killing mycobacteria [30] [31] [32]. In fact, increased production of reactive oxygen species (ROS) by iron 
excess may be detrimental to the host cell itself through induction and acceleration of programmed cell death thereby reducing the survival probability of intracellular organism like mycobacteria [33]. There could be several possibilities which might explain immunity of $M$. tuberculosis to survive in this scenario. Firstly, mycobacterial products like sulfatides and lipoarabinomanan (LAM) can scavenge reactive oxygen intermediates (ROI) or inhibit the respiratory burst that generates them [34]. Secondly, pathogenic mycobacteria reportedly produce large amounts of iron co-factored superoxide dismutase (SOD) capable of detoxifying superoxide anion thereby contributing to virulence of $M$. tuberculosis [35]. Furthermore, M. tuberculosis can enter macrophages via complement receptors, thereby avoiding an oxidative burst [36]. These data suggest that ROS maybe a less powerful antimicrobial tool against $M$ tuberculosis strains in vivo compared to nitric oxide [37].

However, higher incidence of PT in the iron consuming subgroup of HIV-1 infected donors could be an independent direct effect of iron apart from indirect effects through alteration of nitrite/superoxide production. Direct evidence includes demonstration of obligatory requirement of iron for growth of M. tuberculosis in vitro [38], epidemiological evidence includes association between iron overload and pulmonary tuberculosis [39] and genetic evidence shows link between susceptibility of iron overload and tuberculosis [40] while indirect evidence is provided by reported inhibition of growth of $M$. tuberculosis by exogenous chelator [30] and improved clinical outcome in patients with iron overload on administration of chelators [41].

In the present study production of IL-12p70 was found to be markedly deficient at enrolment in the subgroups of donors consuming oral iron as evident from their levels in serum as well as in MDM culture supernatant regardless of whether they developed PT or non-PT category of ARI on follow up, although the degree of depression was significantly more marked in the former category compared to later. Decreased level of IL-12p70 is more likely to be a direct effect of high serum iron rather than deficiency of cooperative effect by cytokine IFN- $\gamma$ since treatment of purified MDMs by IFN- $\gamma$ did not have any effect on IL-12p70 production on PMA or SAC stimulation. Iron overload has been reported to depress production of IL-12 through negative effect on 1L-12 gene expression [42]. There is evidence of defective production of IL-12 in early stage of HIV-1 infection [43]. However, greater magnitude of deficiency in IL-12 production refractory to priming effect by rIFN- $\gamma$ observed at enrolment in the iron consuming subgroup of HIV-1 positive donors that showed development of PT in high proportion $(>70 \%)$ of cases on follow up suggests a relationship between reduced level of IL-12 and increased susceptibility to M. tuberculosis. It has been reported that rIL-12 administration increases and rIL-12 neutralization decreases resistance to $M$. tuberculosis [44]. Treatment with rIL-12 delays lung pathology in M. tuberculosis infected mice [45] which highlights a possible link between IL-12 deficiency and rapid post-PT disease progression reported earlier in 
the same subgroup with iron overload [7].

In the present study, the subgroup of donors negative for HIV-1 infection but with history of iron consumption (subgroup III) showed characteristics of macrophage related immune alterations at baseline similar to HIV-1 positive donors with history of iron consumption as judged by serum levels of pro-inflammatory cytokines, nitrite as well as production of nitrite, superoxide, and IL-12 by cultured MDMs. In our previous study the same subgroups of asymptomatic HIV-1 infected donors i.e. subgroup I and subgroup III with impaired $\mathrm{CD} 4+\mathrm{T}$ cell count shared common features like high serum iron status resulting from excess intake of iron alteration of $\mathrm{Th}_{1} / \mathrm{Th}_{2}$ profile of cytokines and immune activation [7]. Thus it may be worthwhile to explore if increased body iron load could lead to any immunological change resulting in increased susceptibility of an individual towards acquisition of HIV-1 upon exposure to the virus.

The significant correlations observed in the present study between serum ferritin level, nitrite and level of IL-12p70 produced by MDMs in culture in the iron consuming subgroup of HIV-1 positive donors developing PT on follow up suggest an influence of iron overload on the functioning of macrophages. However considering the fact that such alterations were demonstrable in a medium free from donor's blood, it appears that such deficiency was a reflection of an intrinsic defect induced by body iron overload on the macrophages rather than any effect of free iron in the blood. Further, comparable degree of alterations (deficiencies) in the production of nitrite and IL-12p70 by MDMs, regardless of whether primed or unprimed by rIFN- $\gamma$ suggest that such alterations were not due to lack of any stimulatory signal from CD4+ T lymphocytes that are known to provide $\gamma$-IFN mediated stimulatory signal to macrophages for effective killing of intracellular pathogens under physiological conditions.

Infection due to $M$. tuberculosis is known to be very common among HIV-linfected individuals in developing countries including India due to high prevalence of tuberculosis in the community [7]. Numerous studies have demonstrated impairment of macrophage function associated with tuberculosis in established stage of HIV-1 infection [1] [2] [3] [4]. However, there is hardly any study to document association of impaired macrophage function at early asymptomatic stage of HIV-1 infection and future development of pulmonary tuberculosis. While no macrophage abnormality could be detected in early asymptomatic stage of HIV-1 infection in blood donors without any history of oral iron intake in the present study, there was definite evidence of impaired macrophage function in a subset of asymptomatic HIV-1 infected blood donors with iron overload that developed pulmonary tuberculosis on follow up.

The present study emphasizes the need to be concerned about the possible adverse consequences of iron excess in the pathogenesis of HIV-1 infection since adverse immunological changes have also been demonstrated in animal model even when such excess was marginal as shown to happen during administration of iron for prophylactic use e.g. to correct anemia during pregnancy [46]. 


\section{Acknowledgements}

The authors are grateful to Mr. Ashish Datt Upadhyay, Scientist, Department of Biostatics, All India Institute of Medical Sciences, New Delhi for help in the statistical analysis of some data and to Dr. Boney Devi, an MPH Scholar, for some constructive suggestions in the analysis of data. The authors are also grateful to the blood donors for their cooperation in the study as well as to the blood banks in the city of Delhi for referring the donors screened to be positive for HIV-1 infection.

\section{References}

[1] Ismail, N., Olano, J.P., Feng, H.M. and Walker, D.H. (2002) Current Status of Immune Mechanisms of Killing of Intracellular Microorganisms. FEMS Microbiology Letters, 207, 111-120.

[2] Harris, J., De Haro, S.A., Master, S.S., Keane, J., Roberts, E.A., Delgado, M. and Diretic, V. (2007) T Helper 2 Cytokines Inhibit Autophagic Control of Intracellular Mycobacterium tuberculosis. Immunity, 27, 505-517. https://doi.org/10.1016/j.immuni.2007.07.022

[3] Weiss, G. and Schaible, U.E. (2015) Macrophage Defense Mechanisms against Intracellular Bacteria. Immunological Reviews, 264, 182-203.

[4] Herbst, S., Schaible, U.E. and Schneider, B.E. (2011) Interferon Gamma Activated Macrophages Kill Mycobacterium by Nitric Oxide Induced Apoptosis. PloS ONE, 6 , e19105. https://doi.org/10.1371/journal.pone.0019105

[5] Romani, L., Puccetti, P. and Bistoni, F. (1997) Interleukin-12 in Infectious Diseases. Clinical Microbiology Reviews, 10, 611-636.

[6] Fulton, S.A., Johnsen, J.M., Wolf, S.F., Sieburth, D.S. and Boom, W.H. (1996) Interleukin-12 Production by Human Monocytes Infected with Mycobacterium tuberculosis: Role of Phagocytosis. Infection and Immunity, 64, 2523-2531.

[7] Chattopadhya, D. and Baveja, U. (2018) High Incidence of Pulmonary Tuberculosis in ART Naive Remunerated Blood Donors with Human Immunodeficiency Virus Type-1 Infection: Possible Role of Iron Overload. Journal of Biosciences and Medicine, 6, 62-82. https://doi.org/10.4236/jbm.2018.62006

[8] Barnes, P.F., Abrams, J.S., Lu, S., Sieling, P.A., Rea, T.H. and Modlin, R.L. (1993) Patterns of Cytokine Production by Mycobacterium-Reactive Human T-Cell Clones. Infection and Immunity, 61, 197-203.

[9] Boom, W.H., Wallis, R.S. and Chervenak, K.A. (1991) Human Mycobacterium tuberculosis-Reactive CD4+ T-Cell Clones: Heterogeneity in Antigen Recognition, Cytokine Production, and Cytotoxicity for Mononuclear Phagocytes. Infection and Immunity, 59, 2737-2743.

[10] Zang, M., Gong, J., Iyer, D.V., Jones, B.E., Modlin, R.L. and Barnes, P.F. (1994) T Cell Cytokine Responses in Person with Tuberculosis and Human Immunodeficiency Virus Infection. Journal of Clinical Investigation, 94, 2435-2442. https://doi.org/10.1172/JCI117611

[11] World Health Organisation (1994) Expanded WHO Case Definition for AIDS Surveillance. Weekly Epidemiological Record, 69, 273-275.

[12] Moshage, H., Kok, B., Huizenga, J.R. and Jansen, P.L. (1995) Nitrite and Nitrate Determinations in Plasma: A Critical Evaluation. Clinical Chemistry, 41, 892-896.

[13] Boyde, T.R.C. and Rahmatulla, M. (1980) Optimisation of Conditions for the Colo- 
rimetric Determination of Citrulline, Using Diacetyl Monoxime. Analytical Biochemistry, 107, 424-431.

[14] Bose, M., Farnia, P., Sharma, S., Chattopadhya, D. and Saha, K. (1999) Nitric Oxide Dependent Killing of Mycobacterium tuberculosis by Human Mononuclear Phagocytes from Patients with Active Tuberculosis. International Journal of Immunopathology and Pharmacology, 12, 69-79.

[15] Torre, D., Ferrario, G., Speranza, F., Martegani, R. and Zeroli, C. (1996) Increased Levels of Nitrite in the Sera of Children Infected with Human Immunodeficiency Virus Type 1. Clinical Infectious Diseases, 22, 650-655.

https://doi.org/10.1093/clinids/22.4.650

[16] Byrnes, A.A., Harris, D.M., Atabani, S.F., Sabundayo, B.P., Langan, S.J., Margolick, J.B. and Karp, C.L. (2008) Immune Activation and IL-12 Production during Acute/Early HIV Infection in the Absence and Presence of Highly Active Antiretroviral Therapy. Journal of Leukocyte Biology, 84, 1447-1453. https://doi.org/10.1093/clinids/22.4.650

[17] Holzer, T.Z., Nelson, K.E., Crispen, R.G. and Andersen, B.R. (1986) Mycobacterium leprae Fails to Stimulate Phagocytic Cell Superoxide Generation. Infection and Immunity, 51, 514-520.

[18] Lowry, P.H., Rosebrough, N.J., Farr, A.L. and Randall, R.J. (1951) Protein Measurement with the Folin Phenol Reagent. Journal of Biological Chemistry, 193, 265-275.

[19] Vanham, G., Edmonds, K., Quing, L., Hom, D., Toossi, Z., Jones, B., Daley, C.L., Huebner, B., Kestens, L., Gigase, P. and Ellner, J.J. (1996) Generalized Immune Activation in Pulmonary Tuberculosis: Co-Activation with HIV Infection. Clinical and Experimental Immunology, 103, 30-34. https://doi.org/10.1093/clinids/22.4.650

[20] Wallis, R.S., Helfand, M.S., Whalen, C.C., Johnson, J.L., Mugerwa, R.D., Viecha, M., Okwera, A. and Ellner, J.J. (1996) Immune Activation, Allergic Drug Toxicity and Mortality in HIV-Positive Tuberculosis. Tubercle and Lung Disease, 77, 516-523. https://doi.org/10.1016/S0962-8479(96)90049-0

[21] Pietraforte, D., Tritarelli, E., Testa, U. and Minetti, M. (1994) gp120 HIV Envelope Glycoprotein Increases the Production of Nitric Oxide in Human Monocyte-Derived Macrophages. Journal of Leukocyte Biology, 55, 175-182. https://doi.org/10.1002/jlb.55.2.175

[22] Blond, D., Cheret, A., Raoul, H., Le grand, R., Canfour, P. and Theodero, F. (1998) Nitricoxide Synthesis during Acute SIVmac251 Infection of Macaques. Research in Virology, 149, 75-86. https://doi.org/10.1016/S0923-2516(98)80083-6

[23] Cronje, L. and Bornman, L. (2005) Iron Overload and Tuberculosis: A Case for Iron Chelation Therapy. International Journal of Tuberculosis and Lung Disease, 9, 2-9.

[24] Weiss, G., Werner Felmayer, G., Werner, G.R., Grunewald, K., Wachter, H. and Hantze, M.W. (1994) Iron Regulates Nitric Oxide Synthase Activity by Controlling Nuclear Transcription. Journal of Experimental Medicine, 180, 969-976. https://doi.org/10.1084/jem.180.3.969

[25] Evans, T.G., Rasmussen, K., Wiebe, G. and Hibbs, J.B. (1994) Nitric Oxide Synthesis in Patients with Advanced HIV Infection. Clinical and Experimental Immunology, 97, 83-86. https://doi.org/10.1111/j.1365-2249.1994.tb06583.x

[26] Barnes, P.J. and Belvisi, M.G. (1993) Nitricoxide and Lung Disease. Thorax, 48, 1034-1043. https://doi.org/10.1136/thx.48.10.1034

[27] Denis, M. (1994) Human Monocytes/Macrophages: No or No No? Journal of Leukocyte Biology, 55, 682-684. 
[28] Salmen, S. and Berrueta, L. (2012) Immune Modulators of HIV Infection: The Role of Reactive Oxygen Species. Journal of Clinical and Cellular Immunology, 3, 121. https://doi.org/10.4172/2155-9899.1000121

[29] Hershko, C. (2010) Pathogenesis and Management of Iron Toxicity in Thalassemia. Annals of the New York Academy of Sciences, 1202, 1-9. https://doi.org/10.1111/j.1749-6632.2010.05544.x

[30] Cronje, L., Edmonson, N., Eisenach, K.D. and Bornman, L. (2005) Iron and Chelating Agents Modulate Mycobacterium tuberculosis Growth and Monocyte-Macrophage Viability and Effector Functions. FEMS Immunology and Medical Microbiology, 45, 103-112. https://doi.org/10.1016/j.femsim.2005.02.007

[31] Bogdan, C., Rollinghoff, M. and Diefenbach, A. (2000) Reactive Oxygen and Reactive Nitrogen Intermediates in Innate and Specific Immunity. Current Opinion in Immunology, 12, 64-76. https://doi.org/10.1016/S0952-7915(99)00052-7

[32] Lau, Y.L., Chan, G.C., Hui, Y.F. and Yuen, K.Y. (1998) The Role of Phagocytic Burst in Host Defense against Mycobacterium tuberculosis. Clinical Infectious Diseases, 26, 226-227. https://doi.org/10.1086/517036

[33] Jacob, A.K., Hotchkiss, R.S., DeMeester, S.L., Hiramatshu, M., Karl, I.E., Swanson, P.E., Kobb, J.P. and Buchman, T.G. (1997) Endothelial Cell Apoptosis Is Accelerated by Inorganic Iron and Heat via an Oxygen Radical Dependent Mechanism. Surgery, 122, 243-254. https://doi.org/10.1016/S0039-6060(97)90015-5

[34] Chan, J., Fan, X.D., Hunter, S.W., Brennan, P.J. and Bloom, B.R. (1991) Lipoarabinomannan, a Possible Virulence Factor Involved in Persistence of Mycobacterium tuberculosis within Macrophages. Infection and Immunity, 59, 1755-1761.

[35] Edwards, K.M., Cynamon, M.H., Voladri, R.K.R., Hager, C.C., DeStephano, M.S., Tham, K.T., Lakey, D.L., Bochan, M.R. and Kernodle, D.S. (2001) Iron-Cofactored Superoxide Dismutase Inhibits Host Responses to Mycobacterium tuberculosis. American Journal of Respiratory and Critical Care Medicine, 164, 2213-2219. https://doi.org/10.1164/ajrccm.164.12.2106093

[36] Schlesinger, L.S. (1996) Entry of Mycobacterium tuberculosis into Mononuclear Phagocytes. Current Topics in Microbiology and Immunology, 215, 71-96. https://doi.org/10.1007/978-3-642-80166-2_4

[37] Chan, J., Xing, Y., Magliozzo, R.S. and Bloom, B.R. (1992) Killing of Virulent Mycobacterium tuberculosis by Reactive Nitrogen Intermediates Produced by Activated Murine Macrophages. Journal of Experimental Medicine, 175, 1111-1122. https://doi.org/10.1084/jem.175.4.1111

[38] Raghu, B., Sharma, G.R. and Venkatesan, P. (1993) Effect of Iron on the Growth and Siderophore Production of Mycobacteria. Biochemistry and Molecular Biology International, 31, 341-348.

[39] Gangaidzo, I.T., Moyo, V.M., Mvundura, E., Aggrey, G., Murphree, N.L., Khumalo, H., Saungwene, T., Kasvosve, I., Gomo, Z.A., Rouault, T., Boelaert, J.R. and Gordeuk, V.R. (2001) Association of Pulmonary Tuberculosis with Increased Dietary Iron. The Journal of Infectious Diseases, 184, 936-939. https://doi.org/10.1086/323203

[40] Moyo, V.M., Mandishona, E., Hasstedt, S.J., Gangaidzo, I.T., Gomo, Z.A., Khumalo, H., Saungwene, T., Kiire, C.F., Paterson, A.C., Bloom, P., MacPhail, A.P., Rouault, T. and Gordeuk, V. (1998) Evidence of Genetic Transmission in African Iron Overload. Blood, 91, 1076-1082.

[41] Meyer, D. (2006) Iron Chelation as Therapy for HIV and Mycobacterium tuberculosis Co-Infection under Conditions of Iron Overload. Current Pharmaceutical De- 
sign, 12, 1943-1947. https://doi.org/10.2174/138161206777442164

[42] Mencacci, A., Cenci, E., Boelaert, J.R., Bucci, P., Mosci, P., Fe d'Ostiani, C., Bistoni, F. and Romani, L. (1997) Iron Overload Alters Innate and T Helper Cell Responses to Candida albicans in Mice. The Journal of Infectious Diseases, 175, 1467-1476. https://doi.org/10.1086/516481

[43] Chougnet, C., Wynn, T.A., Clerici, M., Landay, A.L., Kessler, H.A., Rusnak, J., Melcher, G.P., Sher, A. and Shearer, G.M. (1996) Molecular Analysis of Decreased Interleukin-12 Production in Persons Infected with Human Immune-Deficiency Virus. The Journal of Infectious Diseases, 174, 46-53. https://doi.org/10.1093/infdis/174.1.46

[44] Cooper, A.M., Roberts, A.D., Rhoades, E.R., Callahan, J.E., Getzy, D.M. and Orme, I.M. (1995) The Role of Interleukin-12 in Acquired Immunity to Mycobacterium tuberculosis Infection. Immunology, 84, 423-432.

[45] Flynn, J.L., Goldstein, M.M., Triedbold, K.J., Sypek. J., Wolf, S. and Bloom, B.R. (1995) IL-12 Increases Resistance of BALB/c Mice to Mycobacterium tuberculosis Infection. Journal of Immunology, 155, 2515-2524.

[46] Ward, R.J., Wilmet, S., Legssyer, R., Leroy, D., Toussaint, L., Crichton, R.R., Pierreux, C., Hue, L., Piette, J., Srai, S.K., Solanky, N., Klein, D. and Summer, K. (2009) Effects of Marginal Overload on Iron Homeostasis and Immune Function in Alveolar Macrophages Isolated from Pregnant and Normal Rats. BioMetals, 22, 211-223. https://doi.org/10.1007/s10534-008-9155-6 


\section{Supplementary Figure S1}

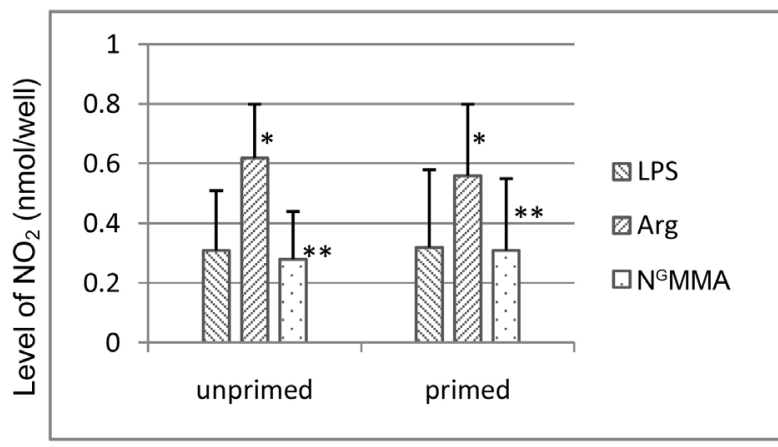

PT Enrolment

(a)

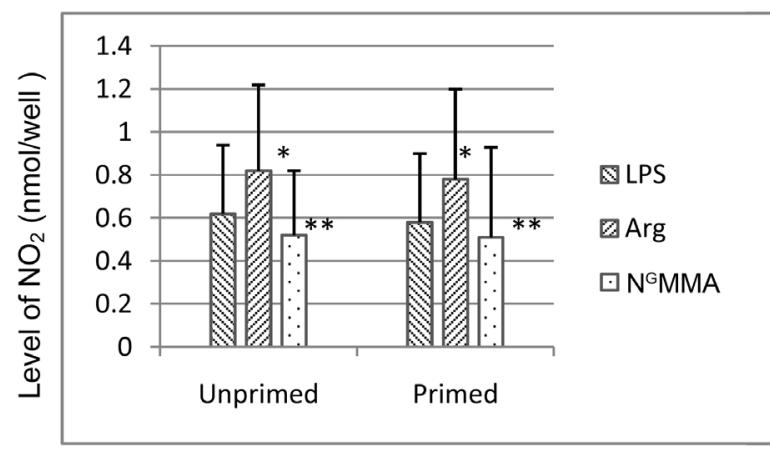

Non-PT Enrolment

(c)

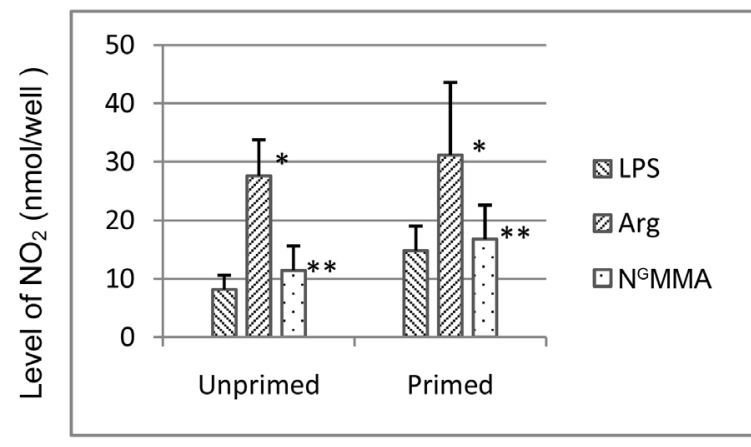

PT Enrolment

(e)

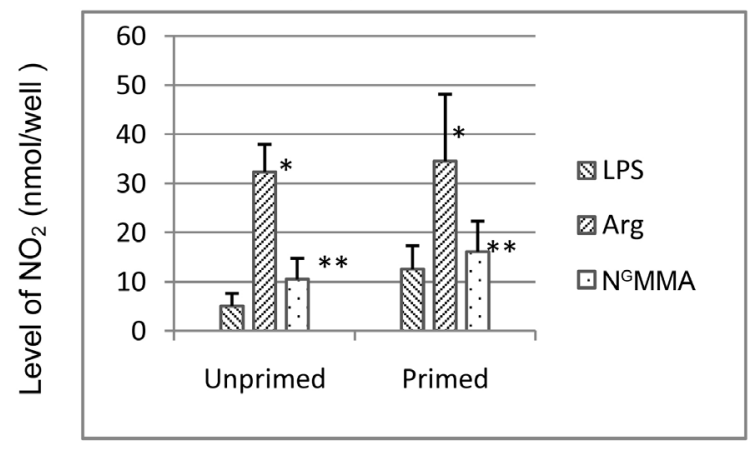

Non- PT Enrolment

(g)

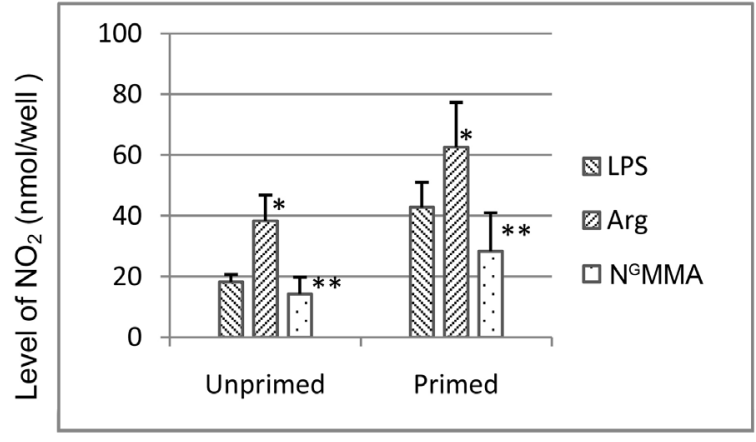

PT Follow up

(b)

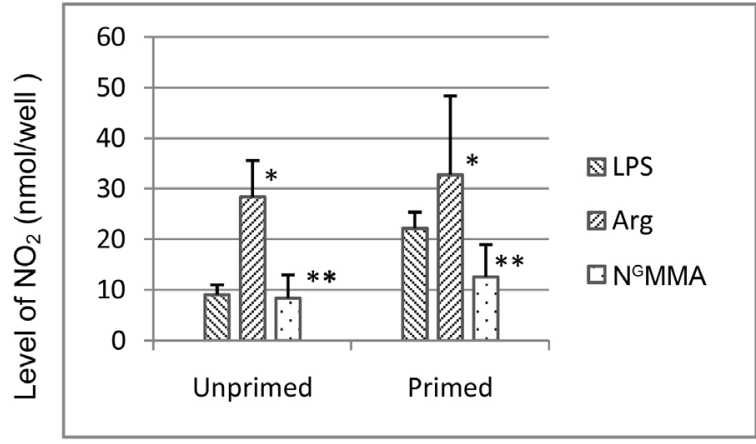

Non-PT Follow up

(d)

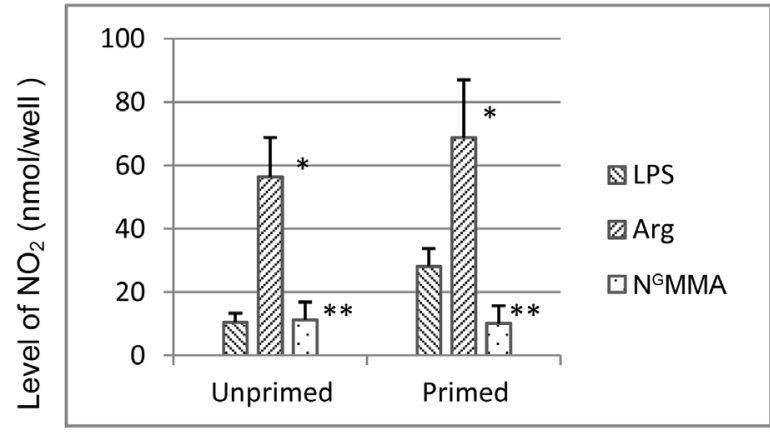

PT Follow up

(f)

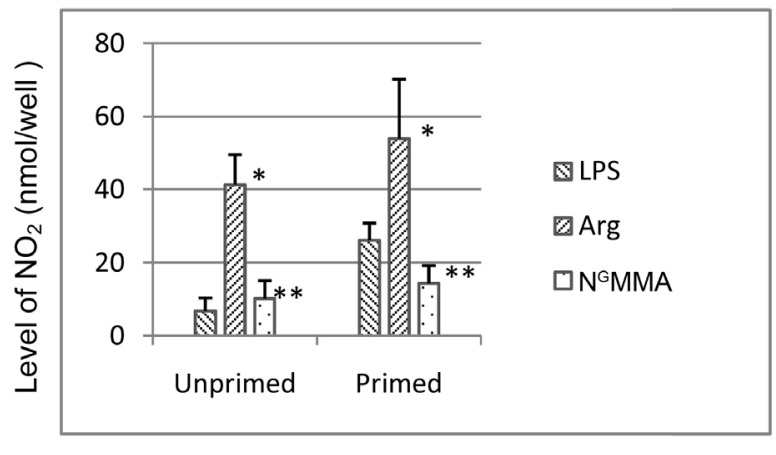

Non-PT Follow up

(h) 


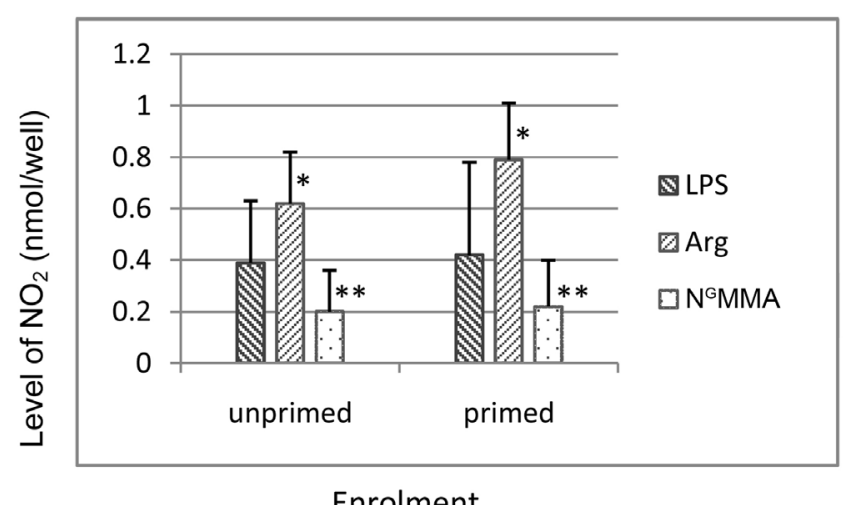

(i)

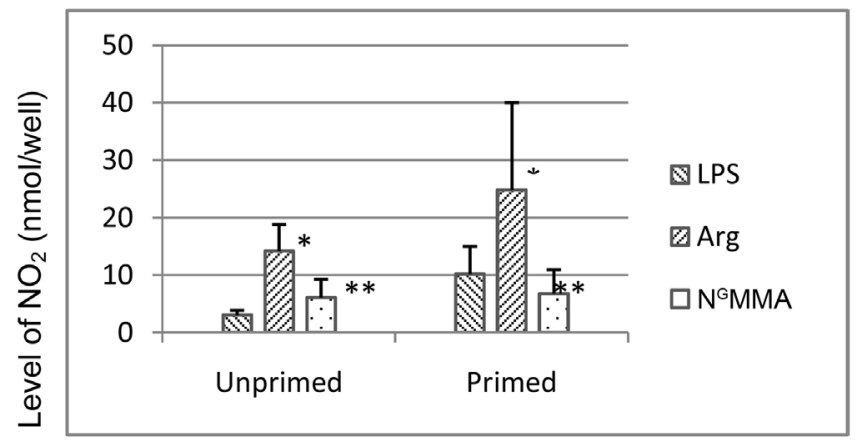

Enrolment

(j)

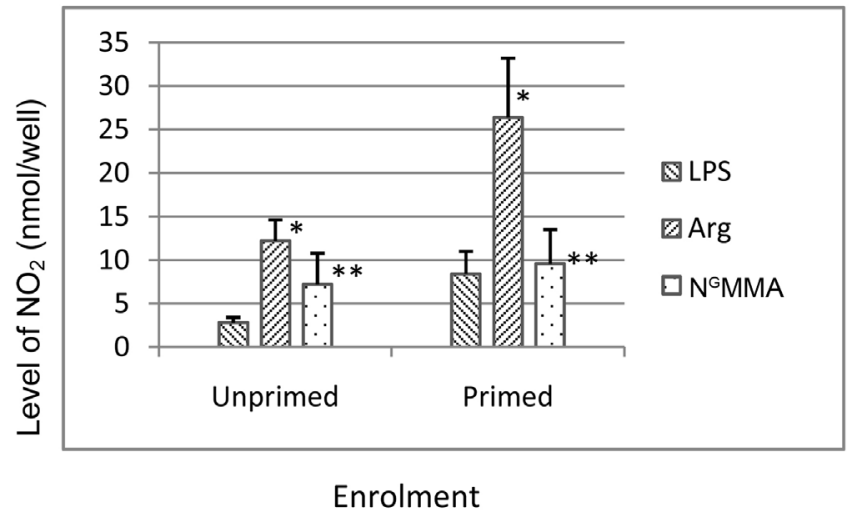

(k)

Figure S1. (a)-(k): Effects of L-Arginine (Arg) and $\mathrm{N}^{\mathrm{G}}$ mono-methyl L-Arginine ( $\mathrm{N}^{\mathrm{G}} \mathrm{MMA}$ ) on production of nitrite by LPS stimulated MDMs, primed and unprimed by $\mathrm{r}$-IFN $\gamma$, in various subgroups of HIV-1 positive blood donors. The values are shown at enrolment and at follow up in relation to categories of ARI i.e. Pulmonary Tuberculosis (PT) or other categories (grouped as non-PT). Figures (a)-(d), (e)-(h), (i), (j) and (k) represent subgroups I, II, III, IV and V respectively. HIV negative donors (Subgroups III and IV) and HIV negative community controls (Subgroup V) did not develop ARI and therefore only enrolment levels are shown. ${ }^{\star}$ Indicates significant elevation $(\mathrm{p}<0.01)$ following treatment with L-Arginine compared to baseline value. ${ }^{\star \star}$ Indicates significant reduction $(\mathrm{p}<0.01)$ in level compared to level following L-Arginine treatment. 


\section{Supplementary Table S1}

Table S1. Levels (Mean \pm SD) of Citrulline and Neopterin as surrogate markers of nitric oxide production by MDM culture at enrolment and at follow up in relation to category of ARI.

\begin{tabular}{|c|c|c|c|c|c|c|c|c|c|}
\hline \multirow{4}{*}{$\begin{array}{l}\text { Surrogate } \\
\text { marker }\end{array}$} & \multirow{4}{*}{$\begin{array}{c}\text { Assessment } \\
\text { point }\end{array}$} & \multirow{4}{*}{$\begin{array}{l}\text { Status of } \\
\text { priming }\end{array}$} & \multicolumn{4}{|c|}{ HIV-1 positive } & \multicolumn{2}{|c|}{ HIV negative } & \multirow{2}{*}{$\begin{array}{c}\text { Community } \\
\text { controls } \\
(\mathrm{Sgr} \mathrm{V})\end{array}$} \\
\hline & & & \multicolumn{2}{|c|}{$\begin{array}{c}\text { Fe pos (Sgr I) } \\
\mathrm{n}=54\end{array}$} & \multicolumn{2}{|c|}{$\begin{array}{c}\text { Fe neg (Sgr II) } \\
n=54\end{array}$} & Fe pos (Sgr III) & Fe neg (Sgr IV) & \\
\hline & & & \multicolumn{2}{|c|}{$\begin{array}{l}\text { Category of ARI on } \\
\text { follow up }\end{array}$} & \multicolumn{2}{|c|}{$\begin{array}{l}\text { Category of ARI on } \\
\text { follow up }\end{array}$} & & & \\
\hline & & & $\begin{array}{c}\mathrm{PT} \\
\mathrm{n}=38\end{array}$ & $\begin{array}{c}\text { non-PT } \\
\mathrm{n}=16\end{array}$ & $\begin{array}{c}\mathrm{PT} \\
\mathrm{n}=10\end{array}$ & $\begin{array}{c}\text { non-PT } \\
\mathrm{n}=44\end{array}$ & $\mathrm{n}=30$ & $\mathrm{n}=50$ & $\mathrm{n}=40$ \\
\hline \multirow{4}{*}{$\begin{array}{l}\text { Citrulline } \\
(\mu \mathrm{M})\end{array}$} & \multirow{2}{*}{ En } & Unpr & $1.5 \pm 0.8^{\text {p. }}$ & $3.1 \pm 1.4^{p}$ & $19.2 \pm 3.9^{\#}$ & $16.4 \pm 3.9^{\#}$ & $2.7 \pm 1.4^{p}$ & $7.2 \pm 4.3$ & $8.4 \pm 3.2$ \\
\hline & & $\operatorname{Pr}$ & $1.6 \pm 0.6$ & $3.9 \pm 1.8$ & $38.6 \pm 6.9^{\dagger}$ & $30.4 \pm 4.7^{\dagger}$ & $2.9 \pm 1.6$ & $19.3 \pm 9.6^{\dagger}$ & $16.6 \pm 8.8^{\dagger}$ \\
\hline & \multirow{2}{*}{$\mathrm{Fu}$} & Unpr & $18.6 \pm 8.2^{\# \S *}$ & $11.4 \pm 2.7^{\# *}$ & $16.2 \pm 7.6^{\#}$ & $21.4 \pm 4.7^{\#}$ & NA & NA & NA \\
\hline & & $\operatorname{Pr}$ & $46.6 \pm 16.8^{\text {st* }}$ & $32.8 \pm 4.7^{\dagger *}$ & $34.3 \pm 8.2^{\dagger *}$ & $38.4 \pm 9.6^{\dagger *}$ & NA & NA & NA \\
\hline \multirow{4}{*}{$\begin{array}{l}\text { Neopterin } \\
\quad(\mu \mathrm{M})\end{array}$} & \multirow{2}{*}{ En } & Unpr & $0.42 \pm 0.21^{P \ddagger}$ & $0.64 \pm 0.26^{?}$ & $5.1 \pm 2.7^{\#}$ & $3.8 \pm 1.7^{\#}$ & $0.49 \pm 0.31^{p}$ & $2.1 \pm 1.4$ & $1.8 \pm 1.2$ \\
\hline & & $\operatorname{Pr}$ & $0.46 \pm 0.32$ & $0.62 \pm 0.21$ & $11.4 \pm 3.8^{\dagger}$ & $9.6 \pm 1.6^{\dagger}$ & $0.51 \pm 0.38$ & $6.1 \pm 2.8^{\dagger}$ & $5.2 \pm 1.8^{\dagger}$ \\
\hline & \multirow{2}{*}{$\mathrm{Fu}$} & Unpr & $8.8 \pm 2.6^{\# \S \star}$ & $4.4 \pm 1.8^{\# \star}$ & $8.2 \pm 3.1^{\#}$ & $5.4 \pm 2.6^{\#}$ & NA & NA & NA \\
\hline & & $\operatorname{Pr}$ & $14.1 \pm 4.5^{\S \dagger \star}$ & $10.2 \pm 3.6^{\dagger *}$ & $12.4 \pm 3.8^{\dagger \star}$ & $9.2 \pm 3.7^{\dagger *}$ & NA & NA & NA \\
\hline
\end{tabular}

1) Sgr I-V = Subgroups I-V; En = Enrolment; Fu = follow up (at the point of development of ARI); PT = Pulmonary tuberculosis; non-PT = category of ARI other than PT; Fe pos and Fe neg $=$ Donors with positive and negative history of oral iron intake; Unpr and $\operatorname{Pr}=$ MDMs Unprimed or Primed by rIFN- $\gamma$; $\mathrm{NA}=$ Not applicable. 2) Statistical comparisons (using multiple comparisons with level of significance at $\mathrm{p}<0.05$ ). "Significant elevation vs. Community

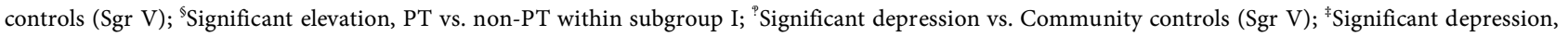
PT vs. non-PT within subgroup II; ${ }^{\dagger}$ Significant augmentation in level on priming of MDMs by rIFN- $\gamma$; ${ }^{*}$ Significant elevation in level at the point of development of ARI on follow up compared to that of enrolment in the corresponding types of MDMs (i.e. primed by rIFN- $\gamma$ or unprimed) for the same category of analyte in corresponding subgroups of blood donors. 